\title{
Infrared Spectroscopy for Analysis of Co-processed Ibuprofen and Magnesium Trisilicate at Milling and Freeze Drying
}

\author{
Manoj Acharya, Satyaki Mishra, Rudra N. Sahoo and Subrata Mallick* \\ Faculty of Pharmaceutical Sciences, Siksha 'O'Anusandhan University, Kalinganagar, \\ Khandagiri Square, Bhubaneswar, OR, India. \\ * Corresponding author: E-mail: subratamallick@soauniversity.ac.in; \\ s_mallickin@yahoo.com; profsmallick@gmail.com \\ Fax: +91-674-2386271; Tel: +91-674-2386209
}

Received: 28-07-2016

\begin{abstract}
Assessment of interactions of ibuprofen and magnesium trisilicate after co-processing has been carried out by infrared spectroscopy. Dry-state ball-milling and, aqueous state kneading and freeze-drying were performed. FTIR spectroscopy of co-processed materials described acid-base reaction between the carboxylic acid containing ibuprofen to a significant extent. Increased absorbance of carboxylate peak accompanied by a consistently reduced absorbance of the carbonyl acid peak was evident. Absorbance of carboxylate peak was more in freeze-dried sample compared to milled product. Intermolecular hydrogen bonding between ibuprofen and magnesium trisilicate in the co-processed material has been suggested. Inhibition of crystal morphology has been noticed in the photomicrographs of both the products. DSC report has shown absence or significantly decreased melting endotherm representing almost complete amorphization of ibuprofen. Release of drug increased greatly after co-processing in comparison to crystalline ibuprofen. Freeze-dried samples have improved drug release more significantly compared to ball-milled samples.
\end{abstract}

Keywords: Infrared spectroscopy; co-milling; co-freeze drying; scanning electron microscopy; differential scanning calorimetry.

\section{Introduction}

Infrared spectroscopy is a workhorse technique for pharmaceutical analysis in recent years. Infrared spectrum represents the molecular absorption and transmission, creating a molecular fingerprint of the sample. It corresponds to the frequencies of vibrations between the bonds of the atoms. Material is a unique combination of atoms and no two compounds produce the exactly same infrared spectrum. Changes in the frequency and shape of the bands of a drug could be utilized for the analysis of possible redistribution of electronic density in the structure of the molecule for the assessment of interactions.

Ibuprofen, the most commonly prescribed NSAIDs ${ }^{1}$ [chemical formula: $\left(\mathrm{CH}_{3}\right)_{2} \mathrm{CHCH}_{2} \mathrm{C}_{6} \mathrm{H}_{4} \mathrm{CH}\left(\mathrm{CH}_{3}\right) \mathrm{COOH}$ ] is known to induce injury of the gastrointestinal tract and cau- se changes in the permeability and structural properties of the membrane. ${ }^{2,3}$ Magnesium trisilicate is used therapeutically as an antacid in the treatment of peptic ulcers. Via a neutralization reaction it increases the $\mathrm{pH}$ of gastric juice. After precipitation colloidal silica can coat gastrointestinal mucosa which can confer further protection. Indigestion, heartburn, or gastroesophageal reflux can sometimes be symptoms of more serious conditions such as stomach ulcers or stomach cancer. Doctor consultation is necessary before taking magnesium trisilicate when an individual is taking a non-steroidal anti- inflammatory drug. Magnesium trisilicate interacts with a number of drugs and alter their absorption, thereby reducing their effectiveness. ${ }^{4-8}$ Enteric coatings designed to prevent the dissolution in the stomach may also be damaged by magnesium trisilicate. ${ }^{9}$ Magnesium trisilicate is a compound of magnesium oxide and silicon dioxide with varying proportions of water $(2 \mathrm{MgO}, 3 \mathrm{SiO} 2, \mathrm{xH} 2 \mathrm{O})$ (USP 28). Magne- 
sium trisilicate is a solid adsorbent and could also be utilized to improve the dissolution of poorly soluble drugs..$^{10,11}$ Solid-dispersion granules of a poorly water-soluble drug containing microporous magnesium aluminosilicate (Neusilin) prepared by hot-melt granulation technique has shown improved dissolution of drug. ${ }^{12,13}$ The solid dispersion granules of BAY 12-9566 containing Neusilin were successfully compressed into tablets and increased dissolution. The hydrogen-bonding potential of silanol groups on the surface of Neusilin brought about the increase in the drug release rate.

In the present study assessment of interactions of ibuprofen and magnesium trisilicate has been undertaken by infrared spectroscopy after milling together in the dry-state and freeze-drying after aqueous state kneading. Ball milling is a powerful tool for particle size reduction and processing in the pharmaceutical industries. ${ }^{14}$ It is also a device for effecting chemical reactions by mechanical energy in dry-state and at ambient temperatures. ${ }^{15,16}$ Ball milling presents a greener route for many processes compared to the use of microwave and ultrasound as energy sources. Impact and attrition during ball milling can bring about changes in the crystal structure of the drug and can induce amorphization ${ }^{17-22}$ and improve bioavailability. ${ }^{23}$ Freeze drying is a standard process used to stabilize and store the drug products in the pharmaceutical industries. ${ }^{24}$ FTIR spectroscopy was monitored to identify the mechanism of interaction ${ }^{25-27}$ of the carboxylic acid-containing drug ibuprofen with magnesium trisilicate. The interaction study has also been monitored by scanning electron microscopy and differential scanning calorimetry (DSC). Afterward, in-vitro drug release from the formulated co-processed powder was carried out to assure about the biological availability of the drug. ${ }^{28}$ The detailed infrared spectroscopy of this type of interaction after co-processing by dry-state milling, and aqueous state equilibration and freeze drying has rarely been reported earlier. Nokhodchi et al., ${ }^{29}$ crystallized ibuprofen in presence of starch derivatives for improved pharmaceutical performance and found no significant change in FTIR spectroscopy and concluded that there is no change in molecular level of ibuprofen. Ibuprofen solid dispersions prepared using polyethylene glycol 4000 have shown no significant change in FT-IR spectra. ${ }^{27}$

\section{Experimental}

\section{1. Materials}

Ibuprofen was obtained from Tejani Life care, Cuttack, India and magnesium trisilicate (USP 28) was purchased from Burgoyne \& Co, India (not less than $20 \%$ of magnesium oxide and not less than $45 \%$ of silicon dioxide; loss on ignition 17.0-34.0\%). All other chemicals used were of analytical reagent grade.

\section{2. Co-processing of Ibuprofen and Magnesium Trisilicate}

Crystalline powder of ibuprofen and magnesium trisilicate powder were mixed for approximately 5 minutes by simple blending process using mortar and spatula at laboratory ambient condition in the dry-state $\left(\sim 30{ }^{\circ} \mathrm{C}\right.$; $\sim 60 \% \mathrm{RH})$ without trituration. Ibuprofen and magnesium trisilicate (physical mixtures) weight ratios (3: 1, 2: 1, 1: 1 and 1:2) were maintained as per formulation and left for immediate use in the co-process of dry-state ball-milling and, aqueous state kneading and freeze-drying.

\section{3. Dry-state Ball-milling}

The powder mixture of ibuprofen and magnesium trisilicate in the weight ratios was placed into a cylindrical vessel of ball mill (Swastik Electric and Scientific Work, India) and $1 \mathrm{~h}$ period of constant milling was performed in the dry-state at lab ambient condition of $\sim 30$ ${ }^{\circ} \mathrm{C}, \sim 60 \% \mathrm{RH}$. Significant increase in temperature of the milled material has not been detected at the end of the co-process. Ball charged in the vessel allowed smooth cascading motion, and significant attrition and impact during dry-state milling while operating the mill at 100 rpm for $1 \mathrm{~h}$.

\section{4. Aqueous State Kneading and Freeze-drying}

Aqueous state kneading was performed by adding small amount of water in the physical powder mixtures of ibuprofen and magnesium trisilicate and left for a period of about $12 \mathrm{~h}$ at ambient conditions for equilibration. The kneaded samples were freeze-dried using a laboratory vacuum freeze dryer $(4 \mathrm{~kg}, 220 \mathrm{~V})$ with attached vacuum $(220 \mathrm{~V}, 2.7 \mathrm{~A}, 370 \mathrm{~W}, 1400 \mathrm{r} / \mathrm{min}, 50 \mathrm{~Hz})$ (Lark, Penguin Classic Plus, India) for 10-12 hours for effective drying. The pressure during freeze-drying was adjusted to $15-20 \mathrm{~Pa}$ while temperature maintained approximately at $-40{ }^{\circ} \mathrm{C}$. The freeze-dried samples were preserved in the desiccator till further analysis.

The ball-milled and freeze-dried samples were left at ambient condition $\left(\sim 60 \% \mathrm{RH}, \sim 30{ }^{\circ} \mathrm{C}\right)$ for few hours and dried in an incubator (Labotech, India) at $50{ }^{\circ} \mathrm{C}$. The powder materials were passed through mesh 44 (opening $\sim 350 \mu \mathrm{m})$ and assayed for drug content determination from the absorbance measured at $222 \mathrm{~nm}\left(\lambda_{\max }\right)$ in the UV visible Spectrophotometer (Jasco-V630 UV Spectrophotometer Spectrometer, Software: Spectra Manager) using standard calibration curve of ibuprofen.

\section{5. Ibuprofen-magnesium Trisilicate Interaction Study}

FTIR spectra of pure crystalline ibuprofen and coprocessed powder samples were performed for a compa- 
rative study between co-milling and co-freeze drying interaction. All the samples were mixed thoroughly with potassium bromide in the ratio of $1: 100 . \mathrm{KBr}$ discs were prepared by compressing the powders at a pressure of 6 tonnes for $10 \mathrm{~min}$ in a Hydraulic pellet press (Technosearch Instruments, Maharashtra, India). FTIR spectrometer (FTIR-4100 type A, Jasco, Tokyo, Japan) was used for collecting all scans from $4000-400 \mathrm{~cm}^{-1}$ of 80 accumulations at a resolution of $4 \mathrm{~cm}^{-1}$ and scanning speed of $2 \mathrm{~mm} / \mathrm{s}$. Spectral Manager for Windows software (Jasco, Tokyo, Japan) was used for data acquisition and holding.

\section{6. Surface Morphology and Thermal Analysis of the Particle}

Surface morphology and crystalline nature of the particulate samples were investigated using Scanning electron microscope (Instrument JSM-6390, Jeol, Tokyo, Japan). The powder samples were dried and sputtered with gold and scanned at room temperature using an accelerated voltage of $10 \mathrm{kV}$ (Wd 19 and Spot_Size 48). Thermal behavior of the powder samples was characterized using a Differential scanning calorimeter (DSC, Universal V4.2E TA Instruments). Samples approximately $5-6 \mathrm{mg}$ were weighed accurately and put into crimped aluminum pans with a pin hole in the lid. All samples were heated at a heating rate of $10{ }^{\circ} \mathrm{C} / \mathrm{min}$ in an atmosphere of nitrogen gas purge at $50 \mathrm{ml} / \mathrm{min}$ from 30 and $300{ }^{\circ} \mathrm{C}$.

\section{7. Drug release Studies}

Powdered samples containing $10 \mathrm{mg}$ equivalent of ibuprofen were dispersed in $900 \mathrm{ml}$ of distilled water and drug release was carried out using USP XXIV type II dissolution apparatus (Electrolab, dissolution tester USP TDT 06L, India) at a temperature of $37 \pm 0.2{ }^{\circ} \mathrm{C}$ and paddle rotation set at $100 \mathrm{rpm}$. Ibuprofen concentration was determined by UV absorption at $222 \mathrm{~nm}$. Aliquots were withdrawn at appropriate time intervals of 5, 10, 15, 30, 60, 90 and $120 \mathrm{~min}$, and replaced with a fresh dissolu- tion medium. After proper rinsing of the cuvette and filtration of the aliquot through a $0.45 \mu \mathrm{m}$ membrane filter, absorbance was recorded using the UV-Visible Spectro photometer. Standard calibration curve was used for calculating the respective concentration and the data were utilized to estimate cumulative percent drug release. $\mathrm{Cu}-$ mulative percent drug release was reported as the mean of not less than three determinations.

\section{Results and Discussion}

The dry-state co-milling and aqueous state co-processing could be analogous to the commonly followed processes in the tablet granulation department of pharmaceutical industries. These processes are effective, simple and scalable for interaction study. Due to presence of varying amount of bound moisture in native magnesium trisilicate the co-milled materials became moisty in nature and needed drying. Instant character of the freeze-dried samples is to absorb moisture like a sponge when left at ambient condition of $\sim 60 \% \mathrm{RH}$ and $30{ }^{\circ} \mathrm{C}$ for few hours and drying in an incubator at $50{ }^{\circ} \mathrm{C}$ becomes necessary. The co-processed dried and equilibrated powder materials were passed through mesh of opening $\sim 350 \mu \mathrm{m}$ and assayed for actual drug content determination. Ibuprofen-magnesium trisilicate interaction study has been characterized by FTIR, and the usefulness of this powerful technique has been supported by scanning electron microscopy and differential scanning calorimetry as described below. Drug release from the formulated dosage form is important and ultimately related to the bioavailability of the drug. Dissolution of ibuprofen from the co-processed material has also been described below. Formulation detail and code of ibuprofen samples coprocessed with magnesium trisilicate has been mentioned in Table 1.

\section{1. FTIR Analysis}

Spectral data of FTIR band assignments of ibuprofen and co-processed samples are tabulated in Table 2.

Table 1. Formulation code of ibuprofen samples co-processed with magnesium trisilicate (Ibuprofen = IB, Magnesium trisilicate = MTS)

\begin{tabular}{cccc}
\hline Formulation code & Drug: MTS ratio & Co-processing & Ibuprofen assay (\%) \\
\hline IB & - & - & - \\
IB1M1pm & $1: 1$ & Physical mixture without trituration & $71.61 \pm 5.1$ \\
IB3M1B & $3: 1$ & Dry-state Ball-milling for one hour & $68.65 \pm 4.6$ \\
IB2M1B & $2: 1$ & Dry-state Ball-milling for one hour & $46.09 \pm 3.5$ \\
IB1M1B & $1: 1$ & Dry-state Ball-milling for one hour & $37.54 \pm 2.8$ \\
IB1M2B & $1: 2$ & Dry-state Ball-milling for one hour & $74.11 \pm 3.2$ \\
IB3M1F & $3: 1$ & Aqueous state equilibration and freeze-drying & $68.55 \pm 3.8$ \\
IB2M1F & $2: 1$ & Aqueous state equilibration and freeze-drying & $48.65 \pm 2.4$ \\
IB1M1F & $1: 1$ & Aqueous state equilibration and freeze-drying & $30.54 \pm 2.1$ \\
IB1M2F & $1: 2$ & Aqueous state equilibration and freeze-drying & \\
\hline
\end{tabular}




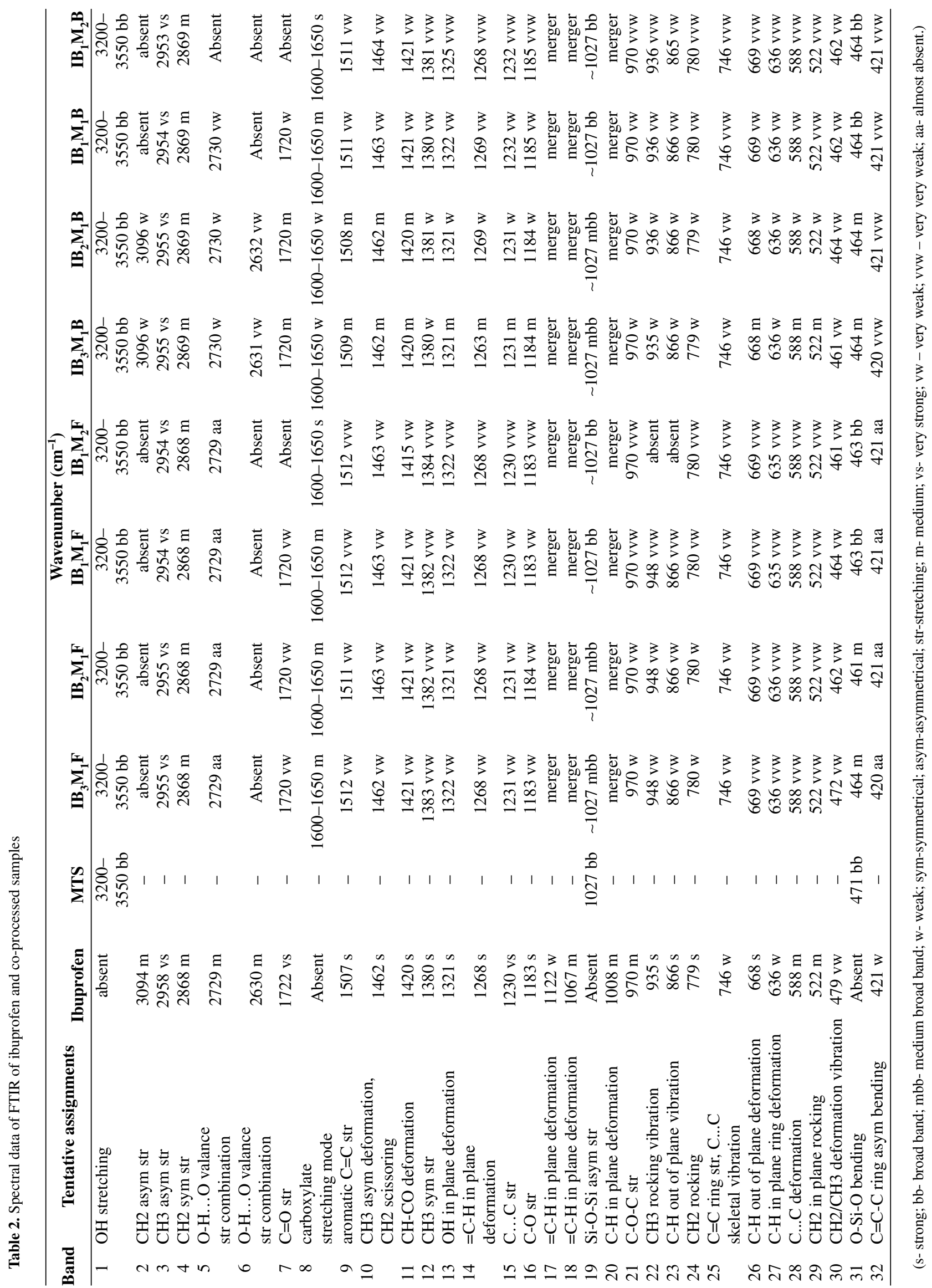


The very strong band at $2958 \mathrm{~cm}^{-1}$ in the FTIR spectrum of ibuprofen is assigned to $\mathrm{CH}_{3}$ asymmetric stretching. ${ }^{30}$ Ibuprofen has also shown the presence of free acid carbonyl peak at $1722 \mathrm{~cm}^{-1}$ with high intensity, ${ }^{27,31}$ but became very weak when co-milled in the dry-state as well as co-freeze-dried after aqueous state kneading and equilibration with magnesium trisilicate (Fig. $1 a, b$ ). As the magnesium trisilicate $\left(2 \mathrm{MgO}, 3 \mathrm{SiO}_{2}, x \mathrm{H}_{2} \mathrm{O}\right)$ contains magnesium oxide (not less than $20 \%$ of magnesium oxide as per USP 28) and the acidic nature of the carboxylic acid group of ibuprofen, the possibility of an acid-base interaction between the drug and $\mathrm{MgO}$ of magnesium trisilicate was explored. Also, very high intensity peak of ibuprofen at $1230 \mathrm{~cm}^{-1}$ was due to C-C stretching ${ }^{32}$ became gradually medium, weak, very weak and absent as the magnesium trisilicate amount increased in both the coprocessed materials $I_{3} M_{1} F$ to $I_{3} M_{2} F$ and $I_{3} M_{1} B$ to $\mathrm{IB}_{1} \mathrm{M}_{2} \mathrm{~B}$. A strong band noticed at $779 \mathrm{~cm}^{-1}$ in ibuprofen was due to $\mathrm{CH}_{2}$ rocking vibration and the intensity observed to be weaker and weaker after co-processing. ${ }^{33,34} \mathrm{CH}_{2}$ asymmetric stretching vibration $\left(3094 \mathrm{~cm}^{-1}\right.$ and $2868 \mathrm{~cm}^{-}$ $\left.{ }^{1}\right)$ and $\mathrm{CH}_{2}$ inplane rocking vibration $\left(522 \mathrm{~cm}^{-1}\right)$ were also detected in pure ibuprofen and found weaker and absent when co-milled and freeze dried after co-kneading. $\mathrm{CH}_{2}$ asymmetric stretching vibration $\left(3094 \mathrm{~cm}^{-1}\right.$ and 2868 $\left.\mathrm{cm}^{-1}\right), \mathrm{CH}_{3}$ asymmetric deformation $\left(1462 \mathrm{~cm}^{-1}\right), \mathrm{CH}_{3}$ rocking of strong intensity $\left(935 \mathrm{~cm}^{-1}\right)$, and $\mathrm{CH}_{2}$ inplane

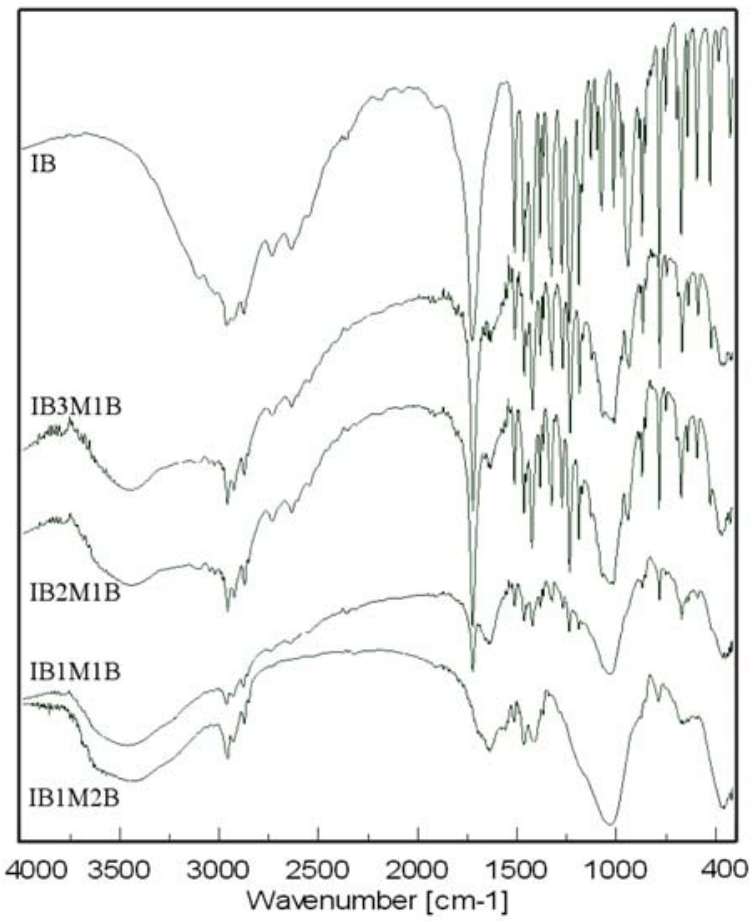

Figure 1. (contd.)Figure 1. FTIR spectroscopy of co-processed ibuprofen and magnesium trisilicate after dry-state ball-milling (a) MTS, IB, IB3M1F, IB2M1F, IB1M1F, and IB1M2F; and aqueous state equilibration and freeze-drying (b) IB, IB3M1B, IB2M1B, IB1M1B, and IB1M2B (abbreviations are explained in Table 1).

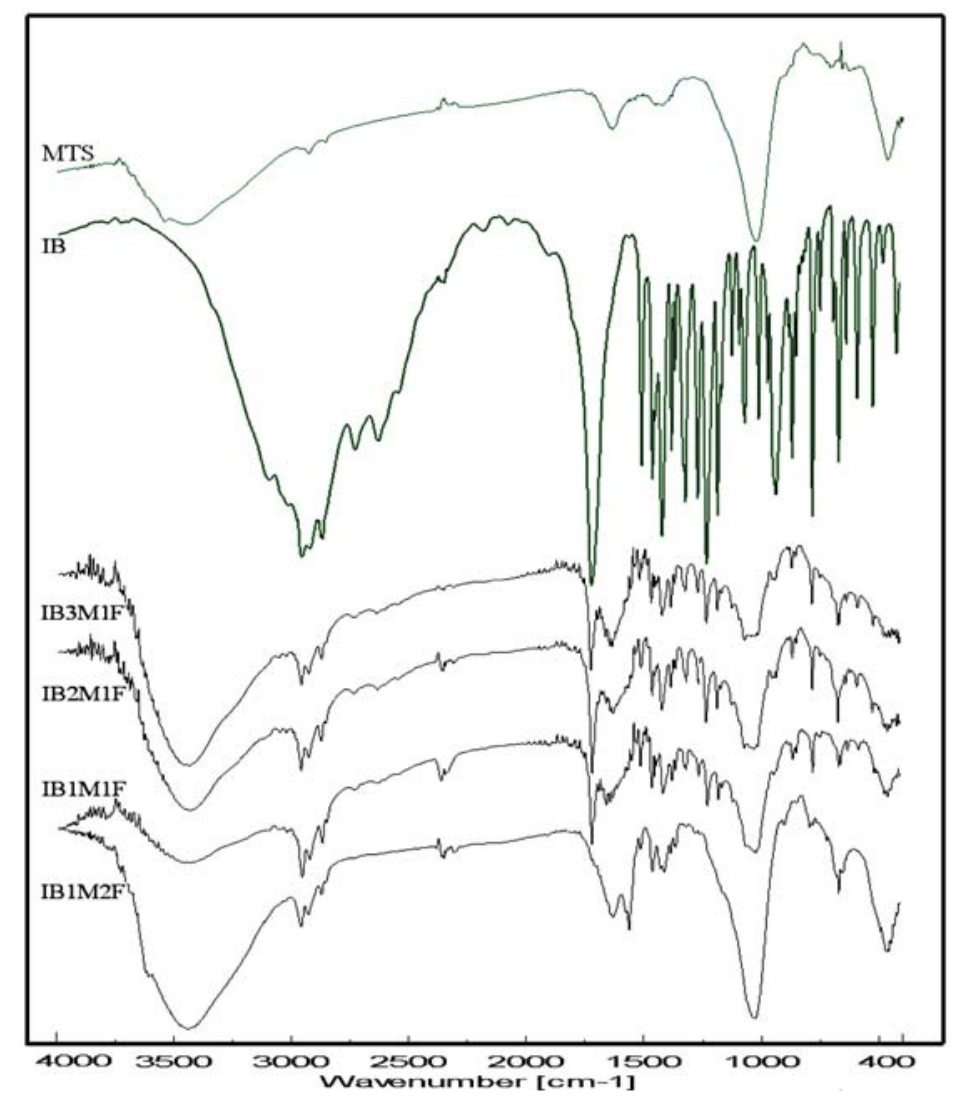

Figure 1. (contd.) 
rocking vibration $\left(522 \mathrm{~cm}^{-1}\right)$ were also detected in pure ibuprofen. Poor band performance was perceived in the co-processed formulations. C-O stretching $\left(1183 \mathrm{~cm}^{-1}\right)$, $\mathrm{CH}_{2}$ scissoring vibration $\left(1462 \mathrm{~cm}^{-1}\right)$ and $\mathrm{CH}-\mathrm{CO}$ deformation $\left(1420 \mathrm{~cm}^{-1}\right)$ contributed their presence strongly in ibuprofen alone and weakly in the co-processed powder. An acid-base reaction between the carboxylic acid containing ibuprofen and $\mathrm{MgO}$ containing MTS in presence of moisture can describe the changes in the FTIR spectra of co-processed formulations. The reaction has been facilita- ted in presence of water when co-freeze-dried after aqueous state kneading and equilibration with magnesium trisilicate and also co-milled in the dry-state containing varying proportions of water in the MTS compound. Carboxylate ion shows peak in the range of $1600-1650 \mathrm{~cm}^{-1}$ in the FTIR spectrum and this change was detected as a function of IB/MTS ratio. A reduction in absorbance of the carbonyl acid peak accompanied by a corresponding increase in the absorbance of carboxylate peak was prominent and the absorbance of carboxylate peak was relatively
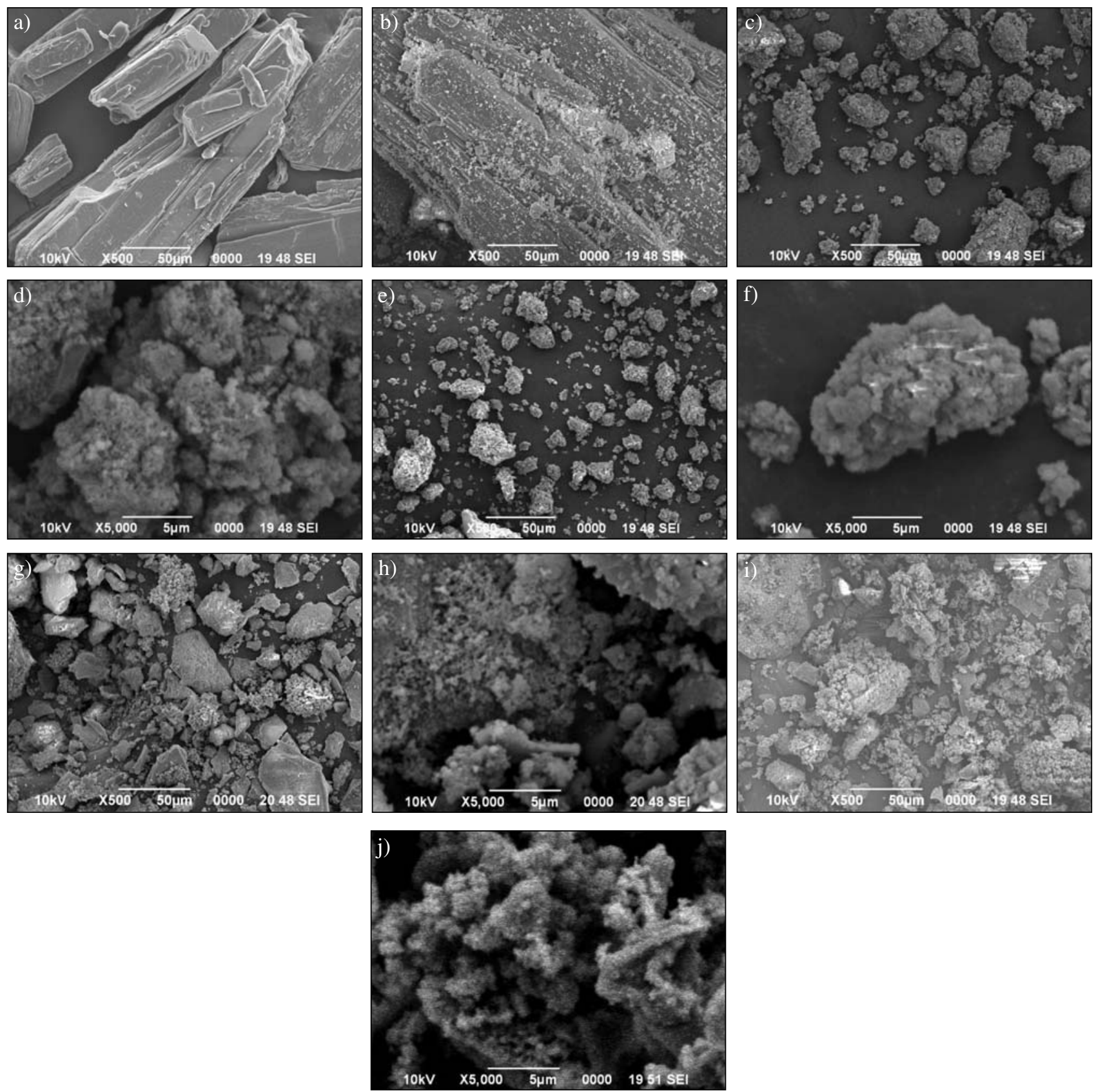

Figure 2. (a) Ibuprofen pure, (b) $I_{1} M_{1} p m$, (c) $I_{1} M_{1} B$ (X500), (d) $I B_{1} M_{1} B$ (X5000), (e) $I_{1} M_{2} B$ (X500), (f) $I_{1} M_{2} B$ (X5000), (g) IB $M_{1} M_{1} F$ (X500), (h) $\mathrm{IB}_{1} \mathrm{M}_{1} \mathrm{~F}$ (X5000), (i) $\mathrm{IB}_{1} \mathrm{M}_{2} \mathrm{~F}$ (1:2)F(X500), and (j) $\mathrm{IB}_{1} \mathrm{M}_{2} \mathrm{~F}$ (X5000) (abbreviations are explained in Table 1). 
more in freeze-dried product compared to milled product. A large broad band between 3550 to $3200 \mathrm{~cm}^{-1}$ ascribed to the presence of the $\mathrm{O}-\mathrm{H}$ stretching frequency of silanol group bonded to the inorganic structure of MTS (containing $\mathrm{SiO}_{2}$ ), and also hydrogen bonds between adsorbed water and silanol. ${ }^{25,35}$ This large broad band is absent in ibuprofen pure drug but consistently maintained in all the co-processed materials could be due to intermolecular hydrogen bonding. The band related to the silanol (Si-O-Si) asymmetric stretching was found at $1027 \mathrm{~cm}^{-1}$ with high intensity in MTS and also in the co-processed formulations. Silanol asymmetric stretching intensity increased with the amount of MTS in the formulation. Another peak at $471 \mathrm{~cm}^{-1}$ in MTS due to O-Si-O bending ${ }^{36}$ prominently observed in the formulations. The small changes in the band intensity, band orientation and overlapping indicated only van der Waals or dipole-dipole interactions between ibuprofen and magnesium trisilicate molecules.

\section{2. Characterization by Scanning Electron Microscopy and Differential Scanning Calorimetry}

Scanning electron microscopy is a powerful tool to study the inhibition of crystal growth morphology. Fig. 2 shows distinctive plate like layers due to the crystalline nature in the initial samples of pure ibuprofen. Physical mixture of drug and magnesium trisilicate in 1:1 ratio $\left(\mathrm{IB}_{1} \mathrm{M}_{1} \mathrm{pm}\right)$ shows the presence of ibuprofen crystal geometry very clearly with slightly damaged morphology. Markedly reduced particle size has been noticed not only in the co-milled materials but also in the freeze-dried formulations after aqueous state kneading and co-processing. Crystal geometry of ibuprofen has been significantly disappeared in both the co-processed materials.

Sub-micron and nano-crystalline agglomeration were observed particularly in the milled material whereas, freeze-dried materials have shown porous bed of irregular nanoparticles developing grain boundaries in the crystal structure indicating loss of crystal geometry. These grain boundaries supposed to disrupt the motion of dislocations and reduce the crystallite size of ibuprofen in the co-processed powder. ${ }^{37}$

Differential scanning calorimetry is frequently used in pharmaceutical research as an analytical tool for the identification and interaction study of active drug after coprocessing with other pharmaceutical compounds. ${ }^{38-43}$ It can explain the miscibility/incompatibility with its effects on thermal stability, yielding results promptly and efficiently. ${ }^{44}$ Thermograms after differential scanning calorimetry of pure ibuprofen and co-processed powder samples are presented in Fig 3. Ibuprofen has shown the melting endotherm at $76.7^{\circ} \mathrm{C}$ which is approximately similar to the literature value. ${ }^{33}$ With the increase of MTS amount in the co-processed material melting temperature and enthalpy (data not mentioned) have been decreased markedly signifying the material is made up of a number of smaller crystals or crystallites, and paracrystalline phases. Melting endotherm of $\mathrm{IB}_{1} \mathrm{M}_{2} \mathrm{~B}$ and $\mathrm{IB}_{1} \mathrm{M}_{2} \mathrm{~F}$ has been disappeared indicating an almost amorphous structure where the atomic position is limited to short range order only. Amorphous phase of ibuprofen could be possible to pro-

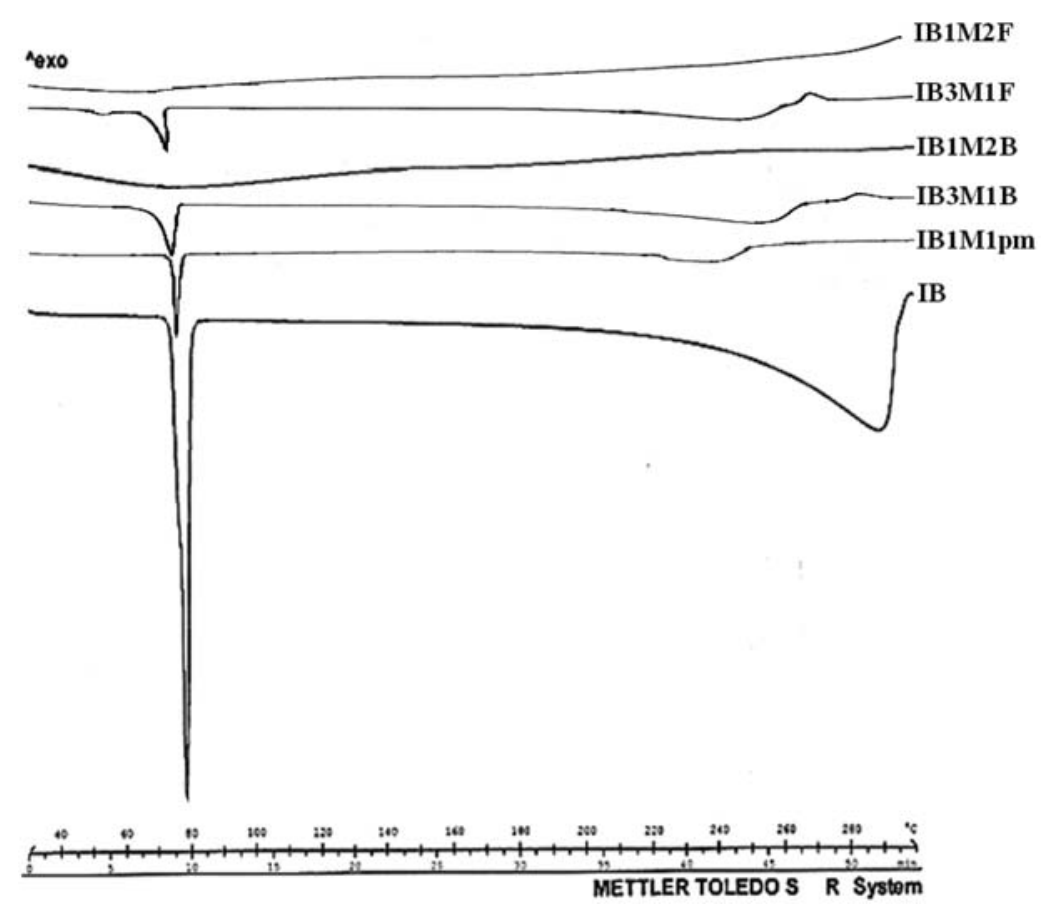

Figure 3. Differential scanning calorimetry of co-processed ibuprofen and magnesium trisilicate after dry-state ball-milling, and aqueous state equilibration and freeze-drying (abbreviations are explained in Table 1). 
duce by solid state co-milling with kaolin. ${ }^{31}$ The interaction between ibuprofen and the porous silica adsorbents indicated a significant loss of crystallinity of ibuprofen by the DSC studies. ${ }^{13}$

\section{3. In-vitro Release of Ibuprofen}

In-vitro drug release profiles of the co-processed material up to 120 min have been depicted in the Fig. $4 a, b$. The powder materials have shown significantly improved dissolution of drug after co-processing. Crystalline ibuprofen exhibited only $52.89 \%$ dissolution whereas, dry-state co-milling of ibuprofen and magnesium trisilicate has improved dissolution to a great extent (77.98 to $85.84 \%$ ). Formulated powder samples of aqueous state co-processing and freeze-drying of ibuprofen and magnesium trisilicate have presented relatively more improved drug release ( 84.87 to $100.29 \%$ ). Percentage release of ibuprofen increased gradually with the gradual increase in magnesium trisilicate proportion in the freeze-dried samples. Mixtures of ibuprofen and magnesium trisilicate have presented substantially higher dissolution compared to the pure drug. Magnesium oxide $(\mathrm{MgO})$ in magnesium trisilicate and carboxylic acid containing ibuprofen brought about the acid-base reaction and the hydrogenbonding potential of silanol groups of $\mathrm{SiO}_{2}$ in the surface of magnesium trisilicate facilitated collectively the increase in the drug dissolution rate. Dissolution of nimesulide from pharmaceutical formulations exhibited better dissolution when the formulations contain micronized nimesulide crystals and medium become alkaline rather than acidic. ${ }^{28}$ Increased proportion of magnesium trisilicate in the mixture might have consumed the carboxylic acid containing ibuprofen and more of hydrogen-bonding potential

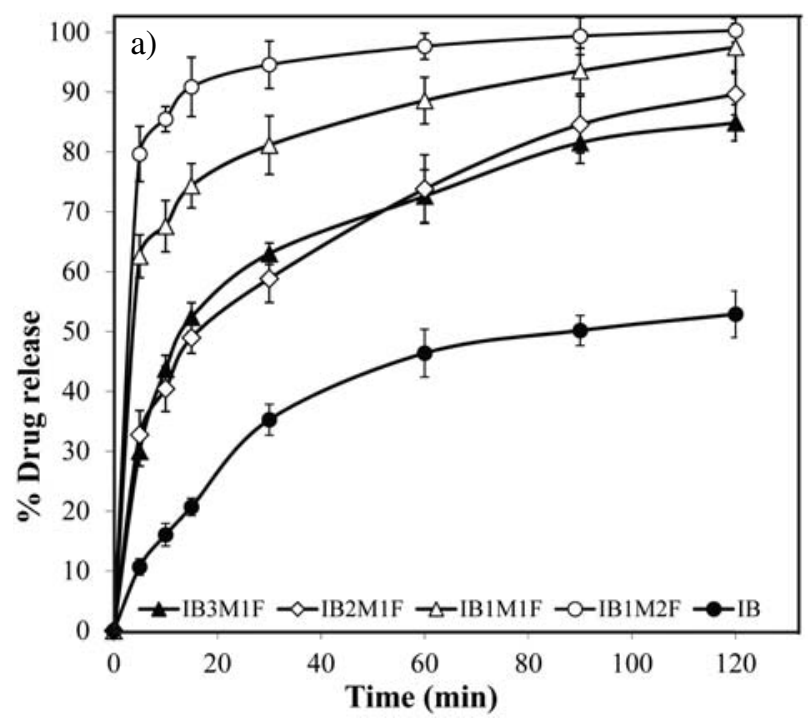

of silanol groups can describe the increased release of ibuprofen of the co-processed formulations. Otsuka et al. have been able to transform the crystalline polymorphs of indomethacin to amorphous states during milling which had $60 \%$ higher dissolution than the crystalline state. ${ }^{20}$ The increased dissolution of drug from solid dispersions possibly be related to the decreased drug crystallinity or effective wetting of the reduced drug particles. ${ }^{45-48} \mathrm{Co}$ processing of ibuprofen with magnesium trisilicate for enhanced dissolution possibly be a promising approach for improvement of ibuprofen bioavailability. ${ }^{47}$

\section{Conclusions}

Detailed infrared spectroscopy has been utilized for the assessment of interactions of ibuprofen and magnesium trisilicate after dry-state ball-milling and, aqueous state kneading and freeze-drying. Changes in the frequency and shape of ibuprofen bands after co-processing have been detected for the analysis of redistribution of electronic density in the structure of ibuprofen molecule. Changes in the FTIR spectroscopy of co-processed formulations can describe acid-base reaction between the carboxylic acid containing ibuprofen and $\mathrm{MgO}$ of magnesium trisilicate $(2 \mathrm{MgO}, 3 \mathrm{SiO} 2, x \mathrm{H} 2 \mathrm{O})$. Varying proportions of water in the magnesium trisilicate facilitated the reaction in the dry-state milling rather gently while, aqueous state equilibration and freeze-drying brought about the reaction considerably. Reduced absorbance of the carbonyl acid peak accompanied by a consistently increase in the absorbance of carboxylate peak was prominently visible and the absorbance of carboxylate peak was rather more in freeze-dried product compared to milled sample.

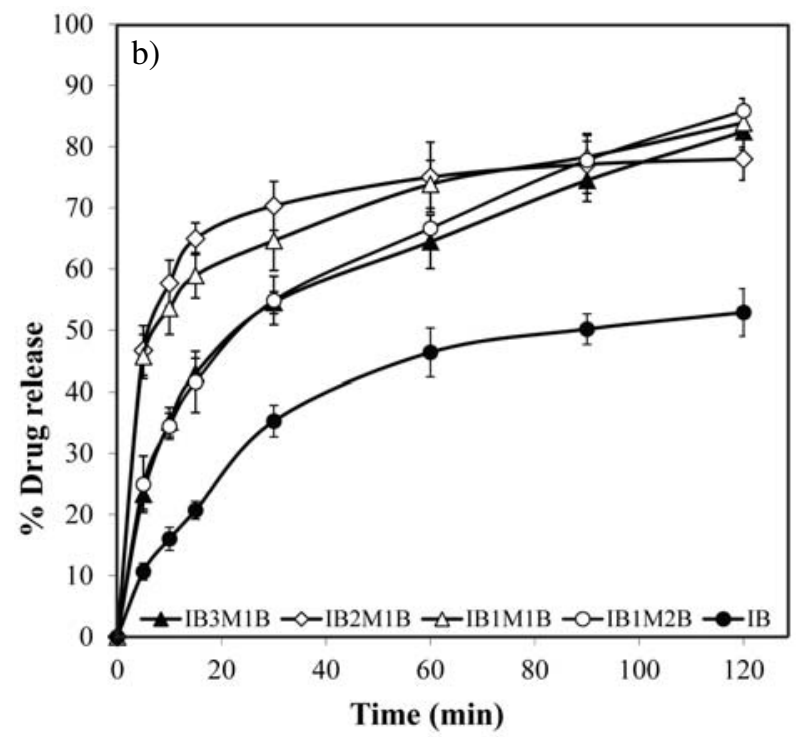

Figure 4. Dissolution profiles of co-processed ibuprofen and magnesium trisilicate: (a) dry-state ball-milling samples; $(b)$ freeze-dried samples after aqueous state equilibration (abbreviations are explained in Table 1). 
$\mathrm{O}-\mathrm{H}$ stretching frequency of silanol group due to the presence of $\mathrm{SiO}_{2}$ in the structure of MTS and the hydrogen bonds between adsorbed water and silanol attributed a large broad band between 3550 to $3200 \mathrm{~cm}^{-1}$ in all the coprocessed materials and not in ibuprofen pure drug spectrum. That is the indication of intermolecular hydrogen bonding between ibuprofen and magnesium trisilicate in the co-processed material. Scanning electron microscopy revealed the inhibition of crystal growth morphology in both the co-processed materials. Milled material has shown sub-micron and nano-crystalline accumulation but, porous bed of irregular nanoparticles with developing grain boundaries was observed in the crystal structure of the freeze-dried samples. Missing of melting endotherm in the DSC report of $\mathrm{IB}_{1} \mathrm{M}_{2} \mathrm{~B}$ and $\mathrm{IB}_{1} \mathrm{M}_{2} \mathrm{~F}$ signified almost complete amorphization of ibuprofen. Significantly decreased melting temperature and enthalpy of ibuprofen in the other co-processed materials indicated inhibition of crystal growth to a great extent. Significantly increased dissolution of drug has been noticed after co-processing compared to crystalline ibuprofen alone. Freeze-dried process presented relatively more enhanced drug release compared to ball-milled samples.

\section{Acknowledgments}

The authors are very much grateful to Prof. Manoj Ranjan Nayak, President, Siksha O Anusandhan University for his inspiration and facilities.

\section{Conflict of Interest \\ None}

\section{References}

1. R. Jones, Am. J. Med. 2001, 110, S4-S7. https://doi.org/10.1016/S0002-9343(00)00627-6

2. L. M. Lichtenberger, Y. Zhou, E. J. Dial, R. M. Raphael, J. Pharm. Pharmacol. 2006, 58, 1421-1428. https://doi.org/10.1211/jpp.58.10.0001

3. C. S. Levin, J. Kundu B. G. Janesko, G. E. Scuseria, R. M. Raphael, N. J. Halas, J. Phys. Chem. B. 2008, 112, 1416814175. https://doi.org/10.1021/jp804374e

4. D. M. Moss, M. Siccardi, D. J. Back, A. Owen, J. Antimicrob. Chemother. 2013, 68, 1627-1634. https://doi.org/10.1093/jac/dkt084

5. V. F. Naggar, S. A. Khalil, M. W. Gouda, J. Pharm. Sci. 1978, 67, 1029-1030. https://doi.org/10.1002/jps.2600670746

6. V. F. Naggar, S. A. Khalil, Clin. Pharmacol. Ther. 1979, 25 , 857-863. https://doi.org/10.1002/cpt1979256857

7. V. F. Naggar, S. A. Khalil, Pharmazie. 1980, 35, 412-416.

8. S. A. Babhair, M. Tariq, Res. Commun. Chem. Pathol. Pharmacol. 1983, 40, 165-168.
9. Magnesium Trisilicate Mixture BP - Summary of Product ... - eMC (Last Updated on eMC 30-Jul-2015)

https://www.medicines.org.uk/emc/medicine/25289

10. F. Carli, E. Chiellini, Pharmaceutical composition comprising a water/oil/water double microemulsion incorporated in a solid support. 2004, Google Patents.

11. X. Pan, The application of porous adsorbents to increase the dissolution rate of low solubility drugs, dissertation. 2002, University of Maryland.

12. M. K. Gupta, D. Goldman, R. H. Bogner, Y-C. Tseng, Pharm. Dev. Technol. 2001, 6, 563-572. https://doi.org/10.1081/PDT-120000294

13. M. K. Gupta, R. H. Bogner, D. Goldman, Y-C. Tseng, Pharm. Dev. Technol. 2002, 7, 103-112. https://doi.org/10.1081/PDT-120002236

14. M. Mihelcic, A. S. Vuk, D. Vrhovsek, F. Svegl, M. Hajzeri, B. Orel, Acta Chim. Slov. 2014, 61, 517-529.

15. T. Friscic, in: A. Stolle, B. Ranu (Ed.): Ball Milling Towards Green Synthesis: Applications, Projects, Challenges, Royal Society of Chemistry, Thomas Graham House, Cambridge, UK, 2015, pp. 151-189.

16. Y. Liu, X. Wang, H. Liu, Z. Dong, S. Li, H. Gea, M.Yan, RSC Adv. 2015, 5, 60460-60466.

17. G. Buckton, A. Choularton, A. E. Beezer, S. M. Chatham, Int. J. Pharm. 1988, 47, 121-128. https://doi.org/10.1016/0378-5173(88)90222-0

18. S. Kitamura, A. Miyamae, S. Koda, Y. Morimoto, Int. J. Pharm. 1989, 56, 125-134.

https://doi.org/10.1016/0378-5173(89)90005-7

19. M. Otsuka, T. Ofusa, Y. Matsuda, Colloids Surf. B: Biointerf. 1999, 13, 263-273. https://doi.org/10.1016/S0927-7765(99)00014-4

20. M. Otsuka, T. Matsumoto, N. Kaneniwa, Chem. Pharm. Bull. 1986, 34, 1784-1793. https://doi.org/10.1248/cpb.34.1784

21. B. Karolewicz, A. Górniak, A. Owczarek, E. ŻurawskaPłaksej, A. Piwowar, J. Pluta, J. Therm. Anal. Cal. 2014, 115, 2487-2493. https://doi.org/10.1007/s10973-014-3661-2

22. H. Al-Hamidi, K. Asare-Addo, S. Desai, M. Kitson, A. Nokhodchi, Drug Dev Ind Pharm. 2015, 41, 1682-1692. https://doi.org/10.3109/03639045.2014.991401

23. E. Klosinska-Szmurlo, M. Grudzien, K. Betlejewska-Kielak, F. Plucinski, J. Biernacka, A. P. Mazurek, Acta Chim. Slov. 2014, 61, 827-834.

24. M. J. Pikal, in: J. C. May, L. Rey, (Ed.): Freeze-Drying/ Lyophilization of Pharmaceutical \& Biological Products, 2004, Marcel Dekker, Inc. New York, U.S.A.

25. A. O. Jorgetto, S. P. Pereira, R. I. V. da Silva, M. J. Saeki, M. A. U. Martines, V. A. Pedrosa1, G. R. de Castro, Acta Chim. Slov. 2015, 62, 111-121.

26. A. Górniak, B. Karolewicz, H Czapor-Irzabek, O. Głdysz, Farmacia, 2016, 64, 244-251.

27. M. Newa, K. H. Bhandari, D. X. Li, J. O. Kim, D. S. Yoo, J. A. Kim, B. K. Yoo, J. S. Woo, H. G. Choi, C. S. Yong, Biol. Pharm. Bull. 2008, 31, 939-945.

https://doi.org/10.1248/bpb.31.939 
28. B. Tubic, A. Uzunovic, S. Pilipovic, Z. Gagic, Acta Chim. Slov. 2016, 63, 193-199. https://doi.org/10.17344/acsi.2015.2168

29. A. Nokhodchi, A. Homayouni, R. Araya, W. Kaialy, W. Obeidat, K. Asare-Addo, RSC Adv. 2015, 5, 46119-46131. https://doi.org/10.1039/C5RA06183K

30. R. M. Silverstein, G. C. Bassler, T. C. Morrill, in: J. Stiefel (Ed.): Infrared spectroscopy: Spectrometric identification of organic compounds, John Wiley and Sons, Singapore, 1991, pp. 91-164.

31. S. Mallick, S. Pattnaik, K. Swain, P. K. De, A. Saha, G. Ghoshal, A. Mondal, Eur J Pharm Biopharm. 2008, 68, 346-351. https://doi.org/10.1016/j.ejpb.2007.06.003

32. S. G. Kazarian, G. G. Martirosyan, Int J Pharm. 2002, 232, 81-90. https://doi.org/10.1016/S0378-5173(01)00905-X

33. A. Nokhodchi, O. Amire, M. Jelvehgari, Daru 2010, 18, 74-83.

34. S. R. Matkovic, G. M. Valle, L. E. Briand, Latin Am Appl Res. 2005, 35, 189-195.

35. E. DeOliveira, J. D. Torres, C. C. Silva, A. A. M. Luz, P. Bakuzis, A. G. S. Prado, J Braz Chem Soc. 2006, 17, 994-999. https://doi.org/10.1590/S0103-50532006000500026

36. A. Carreno, E. Schott, X. Zarate, R. Arratia-Perez, J. C. VegaDe, M. Mardones, J. M. Manriquez, I. Chavez, J Chil Chem Soc. 2011, 56, 692-696.

37. P. R. Cantwell, M. Tang, S. J. Dillon, J. Luo, G. S. Rohrer, M. P. Harmer, Acta Mater. 2014, 62, 1-48. https://doi.org/10.1016/j.actamat.2013.07.037
38. S. Mallick, Indian J Pharm Sci. 2004, 2, 142-147.

39. S. Pattnaik, K. Swain, S. Mallick, Z. Lin, Int J Pharm. 2011, 406, 106-110. https://doi.org/10.1016/j.ijpharm.2011.01.009

40. R. Mohapatra, S. Mallick, A. Nanda, R. N. Sahoo, A. Pramanik, A. Bose, D. Das, L. Pattnaik, RSC Adv. 2016, 6, 3197631987.

41. B. Tita, T. Jurca, G. Rusu, G. Bandur, D. Tita, Rev Chim (Bucharest). 2013, 64, 1089-1095.

42. B. Tita, E. Marian, G. Rusu, G. Bandur, D. Tita, Rev Chim (Bucharest). 2013, 64, 1390-1394.

43. B. Panda, A. S. Parihar, S. Mallick, Int J Biol Macromol. 2014, 67, 295-302. https://doi.org/10.1016/j.ijbiomac.2014.03.033

44. K. Klimova, J. Leitner, Thermochim Acta., 2012, 550, 59-64. https://doi.org/10.1016/j.tca.2012.09.024

45. M. Newa, K. H. Bhandari, D. H. Oh, Y. R. Kim, J. H. Sung, J. O. Kim, J. S. Woo, H. G. Choi, C. S. Yong, Arch. Pharm. Res. 2008, 31, 1497-1507. https://doi.org/10.1007/s12272-001-2136-8

46. H. H. Baek, D. H. Kim, S. Y. Kwon, S. J. Rho, D. W. Kim, H. G. Choi, Y. R. Kim, C. S. Yong, Arch. Pharm. Res. 2012, 35, 683-689. https://doi.org/10.1007/s12272-012-0412-4

47. B. Karolewicz, M. Gajda, A. Owczarek, J. Pluta, A. Górniak, Trop. J. Pharm. Res. 2014, 13, 1225-1232. https://doi.org/10.4314/tjpr.v13i8.5

48. B. Karolewicz, M. Gajda, A. Owczarek, J. Pluta, A. Górniak, Pharmazie, 2014, 69, 589-594.

\section{Povzetek}

Zmes ibuprofena in magnezijevega trisilikata smo pripravili na dva načina: s suhim mletjem in z liofilizacijo vodne raztopine. Nastali zmesi smo preučevali s FTIR spektroskopijo. Opazili smo povečano absorpcijo kaboksilatne skupine povezane $\mathrm{z}$ zmanjšanjem absorbance karbonilne kisline, kar kaže na določeno reakcijo karboksilne kisline v ibuprofenu. Absorbanca karboksilne skupine je bila bolj izrazita v liofiliziranem vzorcu, kar kaže na možne intermolekularne vezi med ibuprofenom in magenezijevim trisilikatom v tem primeru priprave zmesi. Razliko smo opazili tudi na fotomikrografskih posnetkih in pri DSC meritvah tališča. Sproščanje ibuprofena iz liofiliziranega vzorca je hitrejše kot pa iz vzorca, pripravljenega s suhim mletjem. 